\title{
Naturally occurring Girinimbine alkaloid inhibits the proliferation, migration, and invasion of human breast cancer cells via induction of apoptosis and inhibition of MEK/ERK and STAT3 signalling pathways
}

\author{
Lihong Yang ${ }^{1 \otimes}$ and Xuehui Yu² \\ 'Department of Nursing, Medical College of ChiFeng University, Chifeng, Inner Mongolia 024000, China; ${ }^{2}$ Department of Orthopedic, The Cen- \\ tral Hospital of Ningcheng, Chifeng, Inner Mongolia 024200, China
}

The currently used anticancer drugs against breast cancer possess serious side effects, have limited efficacy, and often lead to recurrence of the malignancy. The main aim of this research was to investigate the anticancer potential of Girinimbine, a naturally occurring carbazole alkaloid, against ER-negative breast cancer cells (MDA-MB-453) along with its effects on cell migration and invasion, apoptosis, and MEK/ERK/STAT3 pathway. MTT assay was used to evaluate antiproliferative effects of Girinimbine while a clonogenic assay was used to study cell colony formation. Transwell migration and invasion assays were involved to study its effects on cell migration and invasion. Fluorescence microscopy using acridine orange/ethidium bromide was used to study apoptotic effects of girinimbine which was quantified by annexin v-FITC assay. Effects of girinimbine on MEK/ ERK and STAT3 signalling pathways were evaluated by western blot assay. Results showed that girinimbine exhibited dose-dependent as well as time-dependent antiproliferative effects in MDA-MB-453 cells along with strongly inhibiting the cell colony potency of these cancerous cells. Girinimbine can inhibit both cancer cell migration as well as invasion. Girinimbine has induced potent chromatin condensation and nuclear fragmentation. The percentage of both early and late apoptotic cells increased significantly after girinimbine exposure. The anticancer effects of girinimbine were shown to be mediated via inhibition of the MEK/ERK as well as STAT3 signalling pathways. In conclusion, it may be proposed that girinimbine could be a promising anticancer agent against breast cancer, provided further in-depth studies are carried out.

Key words: Breast cancer, cell migration, alkaloids, apoptosis, flow cytometry

Received: 27 October, 2021; revised: 25 February, 2021; accepted: 20 April, 2021; available on-line: 02 September, 2021

ఐe-mail: elweqk@163.com

\section{INTRODUCTION}

Plants contain a huge variety of phytochemicals including flavonoids, terpenoids, amino acids, sterols, glycosides, and proteins. In addition to these, plants are rich in different carbazole alkaloids, which show various biological activities. Carbazole alkaloids have been shown to have anti-inflammatory, antioxidative, and anticancer effects (Shah et al., 2008). Carbazole alkaloids also show cytotoxic effects in different human cancer cell lines including breast cancer (Goswamia et al., 2010). Murraya koenigii is a major reservoir of carbazole alkaloids and these compounds have been isolated from aerial as well as underground parts. Murraya koenigii, also known as curry tree, grows under tropical or sub-tropical conditions belonging to the family Rutaceae and is native to India. It is a small tree (12-18 feet tall) with a trunk 16 inches in diameter. Its leaves are highly aromatic and are pinnate with $2-4 \mathrm{~cm}$ leaflets. The berries of this plant are edible and have a sweet flavour. $M$. Koenigii is a pharmacologically active plant and shows different biological activities including anticancer activity. The anticancer activity of $M$. Koenigii was mainly reported due to its free radical scavenging and apoptosis inducing property (Wang et al., 2007; Chaudhary, 2020). Different carbazole alkaloids have been isolated from $M$. Koenigii, but girinimbine was the first one (Ramsewak et al., 1999; Chakraborty et al., 1964; Songue et al., 2012). Girinimbine molecule has shown anti-angiogenic, antiinflammatory, immunomodulatory, antioxidant and antitumor activity (Iman et al., 2017; Iman et al., 2015; Kok et al., 2012). Girinimbine has also been reported as an antiproliferative agent against Hep G2 cells mediated via cell cycle arrest and apoptosis (Syam et al., 2011; Mohan et al., 2013). It targets PI3K (phosphatidylinositol-3-kinase)/Akt, mTOR (the mammalian target of rapamycin) and Wnt/ $\beta$-Catenin signalling pathways in human ovarian cancer (Xin \& Muer, 2018). Breast cancer is regarded as the most frequent kind of cancer in women and is also the second leading cause of cancer-related deaths in females in the United States. During the last 10-20 years, there is a significant improvement in the prognosis of patients with breast cancer mainly due to modifications in lifestyle, prompt detection and advanced therapies. The use of conventional chemotherapy has several limitations due to its serious side-effects. In some patients with advanced stage breast carcinoma, there is another growing problem of drug resistance to these chemotherapeutic agents (Siegel et al., 2016; Chang et al., 2019). On diagnosis of $\mathrm{BC}$, patients have very high chances of showing distinct metastatic lesions (Richard et al., 1999; Norton, 1999; Morrow et al., 1999; Ruppert et al., 1997). Due to distant metastasis and poor prognosis, BC has created an urgent situation in the search for novel anticancer agents ( $\mathrm{Li}$ et al., 1995). Currently more attention is being paid towards those therapeutic agents inducing anticancer effects via apoptosis. Natural products have a great potential to act against different human ailments with very few or no side-effects. Presently main focus of researchers and scientists is on natural products. 
Breast cancer has been categorized into two subtypes based on site of infection: non-invasive and invasive breast cancers. The former one being restricted to the ducts only without invasion to the neighboring connective and fatty tissues, while the latter one is more harmful in which cancerous cells invade to neighboring connective and fatty tissues via lobular wall and ducts (Sharma et al., 2010). The invasive breast cancer is highly lethal and accounted for huge mortality, globally. Therefore, the immediate need to develop new therapeutic agents is the need of an hour to control invasive breast cancer. Girinimbine has been recently shown to inhibit breast cancer cells but very little is known about its underlying mechanism and its effects on invasive breast cancer cells (Liu et al., 2021). The current study about girinimbine was undertaken in an attempt to unveil its anticancer activity against invasive cancerous MDAMB-453 breast cells. We have used the MDA-MB-453 cell line in this study because several studies have already reported about its invasive nature (Vranic et al., 2011). We examined for the first time the effects of girinimbine on MDA-MB-453 cells migration and invasion, apoptosis and MEK/ERK and STAT3 signalling pathways.

\section{MATERIALS AND METHODS}

\section{Proliferation assay}

Cell proliferation percentage was assessed via MTT assay (3-(4,5-dimethylthiazol-2-yl)-2,5-diphenyl tetrazolium bromide assay) (purchased from Sigma Chemical Co. (St. Louis, MO, USA). BC MDA-MB-453 cells (obtained from the Shanghai Institute of Biochemistry and Cell Biology (Shanghai, China) were cultured to $80 \%$ confluence at a density of $1 \times 10^{4}$ cells each well in a 96well plate. Cells were allowed to attach in a $\mathrm{CO}_{2}(5 \%)$ incubator at $37^{\circ} \mathrm{C}$. Afterwards, MDA-MB-453 cells were subjected to girinimbine drug (Sigma Chemical Co. (St. Louis, MO, USA) exposure at varying doses of $0,8,16$, 32 , and $64 \mu \mathrm{M}$ for $24 \mathrm{~h}$ and $48 \mathrm{~h}$. Treated cells were then supplemented with $5 \mathrm{mg} / \mathrm{ml}$ of MT'T stock solution in PBS (Thermo Fisher Scientific, Inc., Waltham, MA, USA) and incubated for $4 \mathrm{~h}$. Thereafter, DMSO (Sigma Chemical Co. (St. Louis, MO, USA) (200 $\mu$ l) was added to each well and supernatants were completely discarded followed by gently mixing. The colour then developed was monitored at $550 \mathrm{~nm}$ through a Multiwell Microplate Reader (Thermo Scientific, USA).

\section{Clonogenic assessment}

MDA-MB-453 BC cells were exposed to girinimbine drug with different doses of $0,8,32$ and $64 \mu \mathrm{M}$ for $4 \mathrm{~h}$. Dilution of the cell colonies was performed in agar solution $(0.3 \%)$ followed by redisposing into $35 \mathrm{~mm}$-cultural dishes. The density of cells in each plate was 3000 . When agar solidifies, girinimbine treated cells were then incubated for 12 days. Afterwards, cell colonies were numbered in $2-\mathrm{mm}$ grid culture dishes (Corning) $(<50$ cells).

\section{Determination of cell migratory and cell invasive potency}

Transwell migration assay was executed to analyse cell migratory potency of girinimbine treated MDAMB-453 BC cells. Briefly, target cells were loaded on upper chambers containing RPMI-1640 medium (Thermo Fisher Scientific, Inc., Waltham, MA, USA) at a density of $4 \times 10^{3}$ cells/well and $5 \times 10^{3}$ cells/well for migration and invasion assessment, respectively. Lower chambers of transwell were loaded only with medium comprising of FBS $(10 \%)$ (Thermo Fisher Scientific, Inc., Waltham, MA, USA). Only upper chambers were subjected to girinimbine drug exposure at changing doses viz $0,8,32$ and $64 \mu \mathrm{M}$ for at least $24 \mathrm{~h}$. Treatment with drug was followed by an incubation at $37^{\circ} \mathrm{C}$ for $6 \mathrm{~h}$. Clearance of upper chambers was performed with a cotton swab to eliminate the cells which did not migrate. Formalin and crystal violet with $4 \%$ and $0.1 \%$, respectively, were used for staining of migratory cells for $15 \mathrm{~min}$. Each section was then photographed with $200 \times$ magnification via inverted microscope (Olympus Corporation, Tokyo, Japan). Similarly, cell invasive ability of MDA-MB-453 BC cells was determined except for cell invasion determination of transwells that were coated with Matrigel.

\section{Apoptosis analysis}

BC MDA-MB-453 cells were placed in a 96-well plate for determination of apoptosis and each well contained $2 \times 10^{5}$ cells. Cells were treated with altering girinimbine drug doses of $0,8,32$ and $64 \mu \mathrm{M}$ and incubated for $24 \mathrm{~h}$. Prior to washing with PBS cells were stained with acridine orange/ethidium bromide (AO/ETBR: 10 $\mu \mathrm{M}$ each) (Beyotime Institute of Biotechnology, Haimen, China) solution for $15 \mathrm{~min}$. Treated cells were fixed in 10\% formaldehyde (Sigma Chemical Co. (St. Louis, MO) and subjected to apoptosis assessment under fluorescence microscope (Olympus Corporation, Tokyo, Japan). For annexin V/PI assay, girinimbine treated cells were stained with annexin V/PI (Thermo Fisher Scientific, Inc., Waltham, MA, USA) and apoptosis quantification was performed through flow cytometry (BD, Biosciences, USA). Each experiment was carried out in triplicates to register different events. Data were analyzed using FlowJo software (version 7.6.5; Tree Star, Inc., Ashland, USA).

\section{Western blotting assay}

MDA-MB-453 cells were harvested at $80 \%$ of confluence followed girinimbine drug treatment at varying concentrations of $0,8,32$ and $64 \mu \mathrm{M}$. Treated cells were lysed using lysis buffer (20 mM Tris- $\mathrm{HCl}(\mathrm{pH} 7.5) 150$ mM NaCl, 1 mM Na2EDTA, 1 mM EGTA, 1\% Triton, $2.5 \mathrm{mM}$ sodium pyrophosphate, $1 \mathrm{mM}$ b-glycerophosphate, $1 \mathrm{mM} \mathrm{Na} 3 \mathrm{VO} 4,1 \mu \mathrm{g} / \mathrm{ml}$ leupeptin) (Beyotime Institute of Biotechnology) and within each lysate protein content was quantified by BCA assay Kit (Beyotime, China). Proteins (45 $\mu \mathrm{g} /$ well) were separated by SDSPAGE followed loading on nitrocellulose membranes (equal distribution). The primary antibodies included anti-Bax (1:1,000; Abcam, Cambridge, MA, USA), antiBcl-2 (1:1,000), anti-Erk and anti-phosphorylated (p-) Erk (1:500, Santa Cruz Biotechnology, Inc., Dallas, TX, USA), anti-Akt (1:500) and anti-p-Akt (1:500; Santa Cruz Biotechnology, Inc. USA), anti-STAT3 (1:500; Santa Cruz Biotechnology, Inc. USA), Anti- $\beta$-actin $(1: 1,000$; Santa Cruz Biotechnology, Inc. USA). After washing with TBST three times, goat anti-rabbit $\operatorname{IgG}(1: 10,000$, Santa Cruz Biotechnology, Inc.) conjugated with horseradish peroxidase was incubated for $1 \mathrm{~h}$ at room temperature. Finally, the various protein bands were observed under the enhanced ECL Select Western Blotting Detection Reagent (GE Healthcare Life Sciences, UK). 


\section{Statistical analysis}

All the results were represented as mean and SEM (standard error of means). The numbers presenting $p<0.05$ were taken as statistically significant. Treated and control groups were compared for differences through one way ANOVA.

\section{RESULTS}

\section{Cell proliferation of MDA-MB-453 cells after girinimbine exposure}

The percentage proliferation of MDA-MB-453 BC cells after exposure to girinimbine (Fig. 1) was monitored by performing MT'T assay. Results showed potential time as well as dose-reliant inhibition in the cellular proliferation of target cells by girinimbine. The proliferation percentage at $0,8,16,32$ and $64 \mu \mathrm{M}$ of drug doses were nearly $95 \%, 85 \%, 60 \%, 25 \%$ and $10 \%$ after $24 \mathrm{~h}$ of exposure. After $48 \mathrm{~h}$ of treatment with girinimbine the proliferation percentage observed was $97 \%$, $77 \%$, $42 \%, 10 \%$ and $5 \%$ (Fig. 2). Thus, the results after $24 \mathrm{~h}$ and $48 \mathrm{~h}$ of drug treatment revealed dose as well as time dependent proliferation inhibition of MDA-MB-453 BC cells.

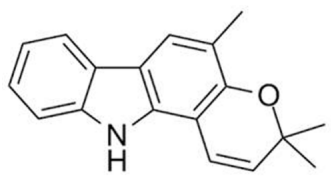

Figure 1. Chemical structure of girinimbine molecule.

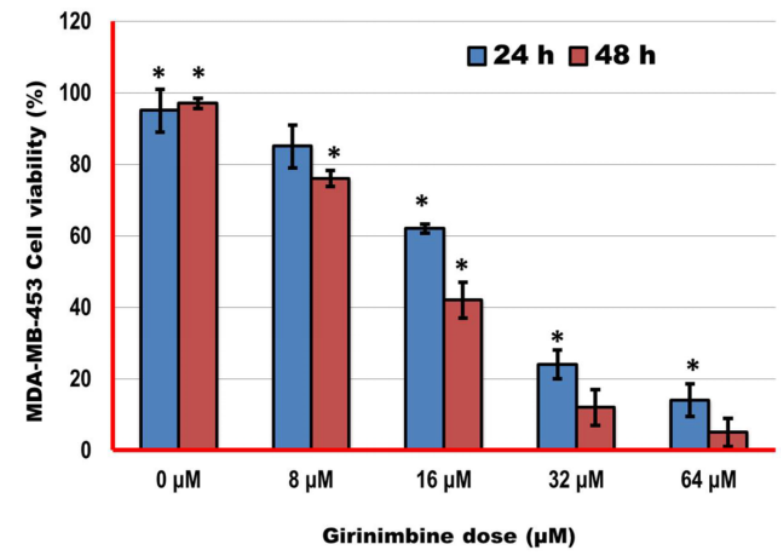

Figure 2. Results representing dose as well time dependent inhibition of cell viability of girinimbine treated MDA-MB-453 breast cancer cells.

Values represent mean \pm S.E.M. of triplicate measurements, ${ }^{*} p<0.05$. More cell viability inhibition was seen at 48 -hour treatment of the tested molecule as compared to 24-hour treatment.

\section{MDA-MB-453 cell colony inhibition by girinimbine}

Cell colonies were analyzed by executing clonogenic assay in $35 \mathrm{~mm}$-culture dishes. Results presented remarkable dose dependent inhibition in the colony forming potency of MDA-MB-453 BC cells. Blue stains in the culture dishes represent cell colonies and these stains can be seen to decrease with increasing girinimbine drug doses (Fig. 3A and Fig. 3B).
$0 \mu \mathrm{M}$

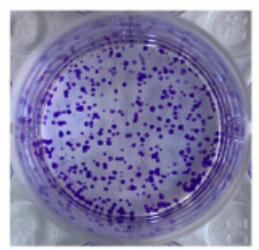

$32 \mu \mathrm{M}$

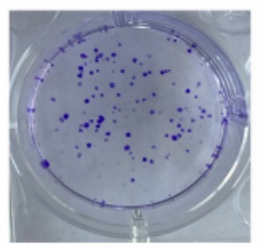

$8 \mu \mathrm{M}$

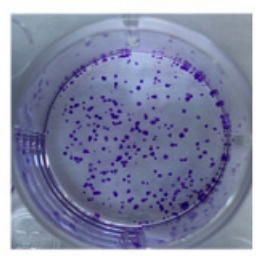

$64 \mu \mathrm{M}$

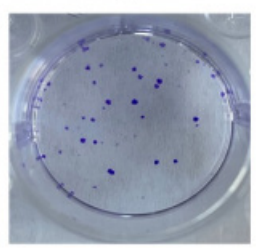

Figure 3A. Clonogenic survival rate reduction after girinimbine treatment of MDA-MB-453 cells. The cells were stained with crystal violet $(0.5 \% \mathrm{w} / \mathrm{v})$ and then photographed, and the cell number was counted.

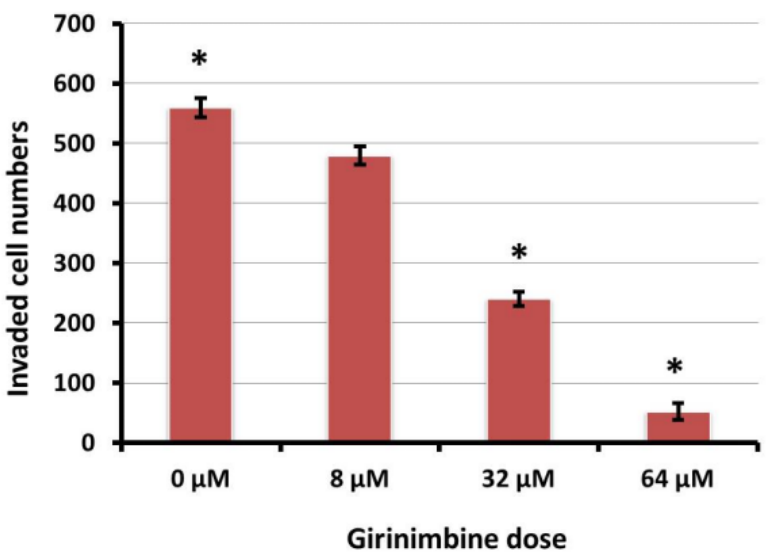

Figure 3B. Graphical representation of the colony formation inhibition induced by girinimbine treatment. Individual experiments were repeated three times.

Values represent mean \pm S.E.M. of triplicate measurements, ${ }^{*} p<0.05$.

Girinimbine supressed cell migratory and cell invasive ability of MDA-MB-453 cells

Transwell chambers assay was performed to check cell invasive as well as cell migratory potential of MDAMB-453 cells. In the case of cell invasion transwell chambers were coated with Matrigel. Results showed remarkable dose dependent decrease of cell invasion and cell migration. At lower drug doses the cell migration only reduced by a small margin but on increasing drug concentration it reduced significantly and effectively (Fig. 4A and Fig. 4B). Similar effects were observed in case of cell invasion, and the number of invaded cells decreased with increasing doses of girinimbine (Fig. 5A and Fig. 5B).

\section{Girinimbine induced apoptotic cell death in MDA- MB-453 cells}

Girinimbine supressed cell viability in MDA-MB-453 cells and it was tested whether the inhibitory effect on 

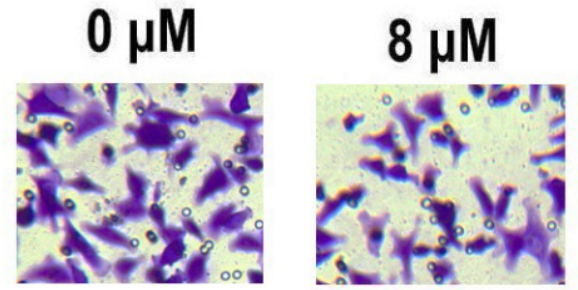

$32 \mu \mathrm{M}$

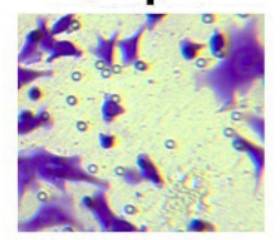

$64 \mu \mathrm{M}$

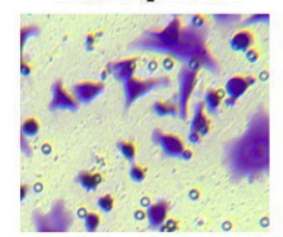

Figure 4A. Results representing cell migration potency of MDAMB-453 cells after girinimbine treatment at indicated doses. After treatment, cells were stained with crystal violet and formalin and then photographed with an inverted microscope to determine the number of migrated cells.

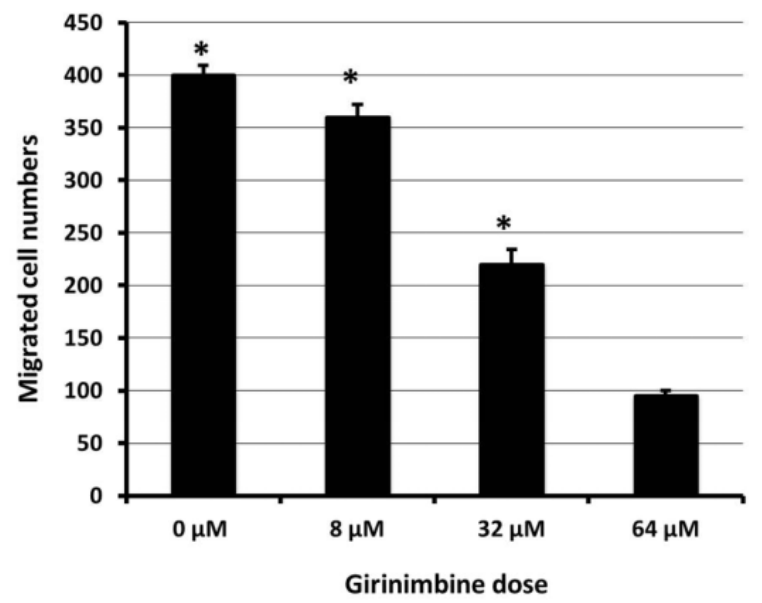

Figure 4B. Graphical representation (quantitative estimation) of the migration inhibitory effects induced by girinimbine treatment. Values represent mean \pm S.E.M. of triplicate measurements, ${ }^{*} p<0.05$.

proliferation is dependent on apoptosis. For that AO/ ETBR staining assay was performed. Results showed that untreated cells were observed with light green fluorescence, while the induction of apoptosis can be easily observed due to the yellow and red fluorescent cells, the number of which increased with the dose of the drug (Fig. 6). Further, quantification of apoptosis was performed by annexin V/PI assay, and it showed that the apoptotic cell percentage enhanced from $2.1 \%$ at control to $56.2 \%$ at $64 \mu \mathrm{M}$ of drug concentration, increasing both early and late apoptotic cell percentage (Fig. 7). In addition to this, western blotting analysis was executed to monitor apoptosis regulatory proteins. It showed dose reliant downregulation of BCL-2 and upregulation of BAX proteins (Fig. 8). Thus, the results from DAPI staining, annexin V/PI assay and western blotting analysis suggested that the antiproliferative effects of girinimbine are apoptosis mediated.
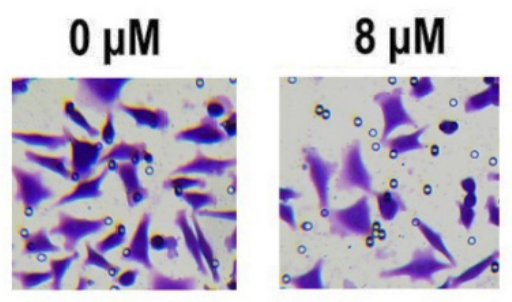

$32 \mu \mathrm{M}$

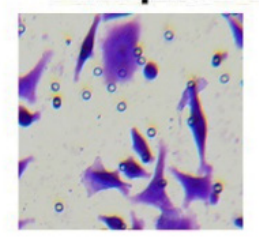

$64 \mu \mathrm{M}$

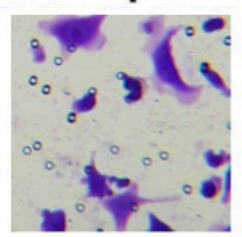

Figure 5A. Results representing cell migration potency of MDAMB-453 cells after girinimbine treatment at indicated doses. Individual experiments were repeated three times.

After treatment, cells were stained with crystal violet and formalin and then photographed with an inverted microscope to determine the number of invaded cells.

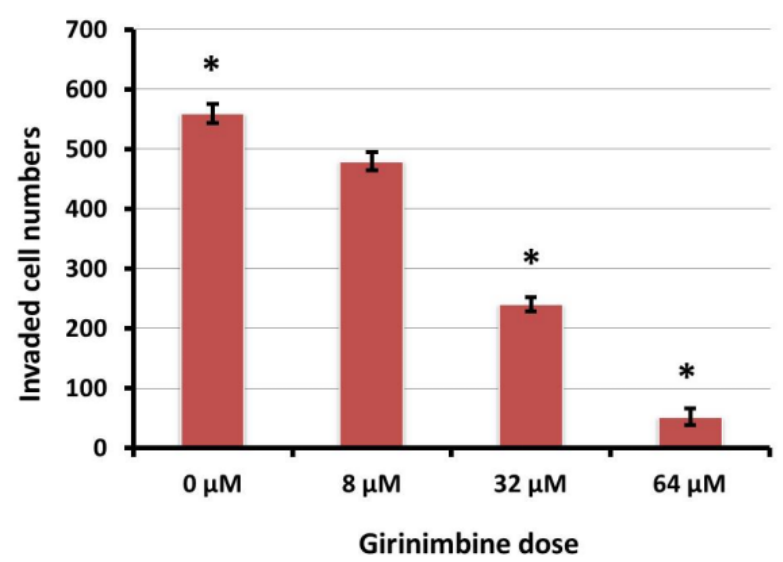

Figure 5B. Graphical representation (quantitative estimation) of the invasion inhibitory effects induced by girinimbine treatment. Values represent mean \pm S.E.M. of triplicate measurements, ${ }^{*} p<0.05$.

Girinimbine targeted the MEK/ERK and STAT3 signalling pathways in MDA-MB-453 cells

To analyse the MEK/ERK and STAT3 signalling pathways after girinimbine treatment of MDA-MB-453 cells, western blotting assay was performed. Results confirmed that the expressions of proteins associated to MEK/ERK and STAT3 signalling pathways were significantly reduced on changing drug concentrations $(0,8$, $16,32$ and $64 \mu \mathrm{M})$. The expressions of $\mathrm{p}-\mathrm{MEK}, \mathrm{MEK}$, p-ERK and p-STAT-3 reduced and ERK increased with increasing drug doses (Fig. 9). The expressions of STAT3 almost remained constant with all drug doses.

\section{DISCUSSION}

Different studies have shown that natural products affect extrinsic and intrinsic pathways of apoptosis. These pathways have been evaluated in relation to many human cancer cell lines including MDA-MB-453 cells. Two 

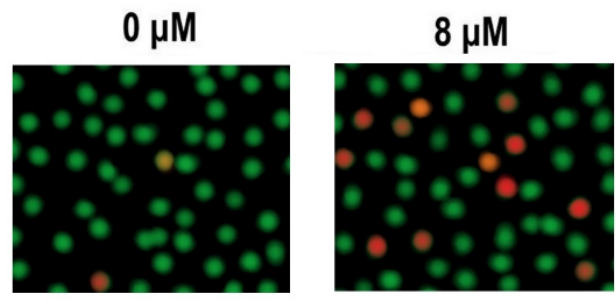

$32 \mu \mathrm{M}$

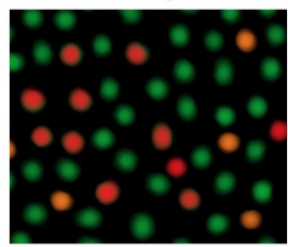

$64 \mu \mathrm{M}$

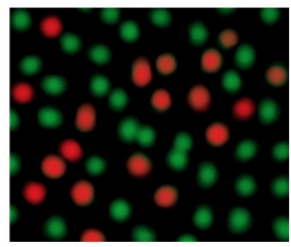

Figure 6. Acridine orange/ethidium bromide staining representing apoptotic MDA-MB-453 breast cancer cells after girinimbine exposure.

Individual experiments were repeated three times. Yellow and red fluorescence indicate cells which have undergone apoptosis. Green cells represent viable cells.

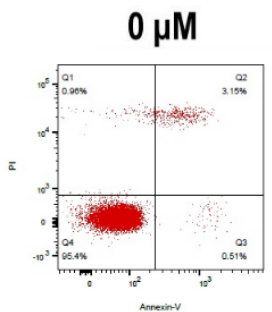

$32 \mu \mathrm{M}$
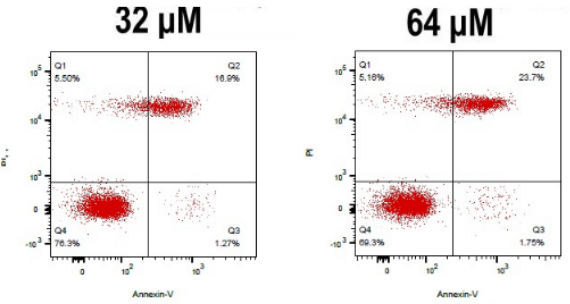

Figure 7. Annexin V/PI assay results revealing the dose dependent increase in the percentage of apoptotic cells.

types of proteins regulate apoptosis in a cancer cell that is proapoptotic (BAX) and antiapoptotic (BCL-2), both belong to BCL-2 family of proteins. Targeting STAT-3 pathway in a cancer cell by natural products is reported to be associated with declination in BCL-2 expression and enhancement in BAX expressions (Fan et al., 2014; Wang et al., 2014). Increased BAX and decreased BCL-2 expressions indicate the apoptotic cell death in a target cancer cell. Breast cancer is a dangerous malignancy prevailing in women globally and its incidences are increasing at an alarming rate. To tackle breast cancer novel treatment strategies are required. There are huge challenges for the scientists in cancer chemotherapy as the cancer cells acquire drug resistance. Breast cancer cells also acquire multidrug resistance which leads to the failure or limitation of the conventional chemotherapy. As such there is a pressing need for novel anticancer drugs which render the cancer cells to undergo cell suicide.
Girinimbine dose

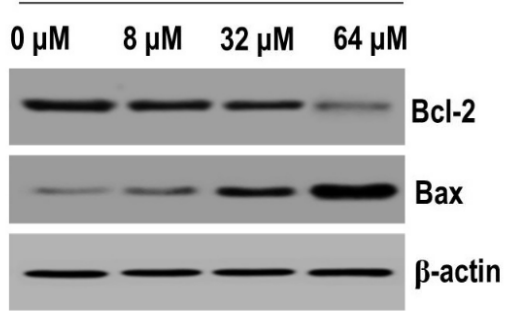

Figure 8. Western blotting assay representing the expressions of pro and anti-apoptotic proteins at indicated girinimbine doses.

Girinimbine dose

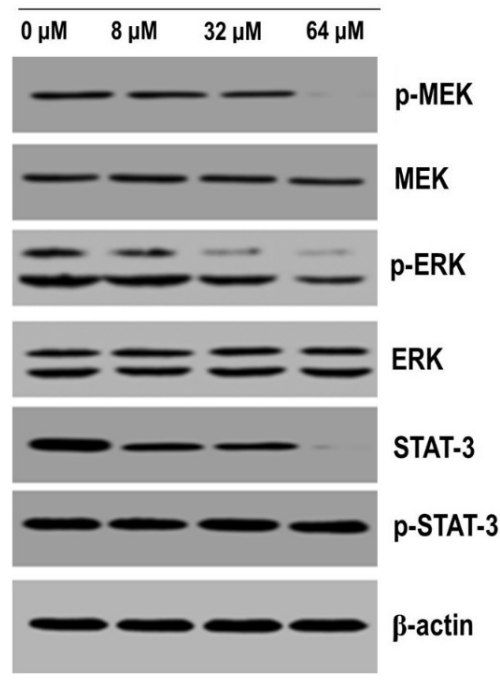

Figure 9. Western blotting assay representing the expressions of MEK/ERK and STAT3 signalling pathways allied proteins at indicated girinimbine doses.

This kind of cell death is referred to as apoptotic cell death. Natural products have been known for a long time to induce cellular apoptosis in cancer cells and as such have the potential to be developed as promising anticancer agents (Khursheed \& Jain, 2020). The main advantage of using an apoptotic anticancer agent is to eliminate the serious side-effects which are mostly seen in conventional chemotherapy (Wu et al., 2019; Hu et al., 2019; Daniel et al., 2006). Present study was designed to examine the anticancer effects of girinimbine on MDAMB-453 breast cancer cell line. Results indicated potential time-reliant as well as dose-reliant inhibition in cell proliferation of MDA-MB-453 cells by girinimbine. Girinimbine is a natural product and natural products are considered as less hazardous to living systems and therefore safer to use. Girinimbine could also inhibit cancer cell colony formation tendency of these target cells. Further, we carried out various bioassays to determine the anticancer mode of action of this molecule. Transwell cell migration and cell invasion assays showed that the girinimbine could significantly supress the ability of cell migration and invasion of MDA-MB-453 cells. This may be a promising feature of this molecule to not allow the breast cancer cells to migrate and invade other nearby tissues/cells. Various apoptotic assays showed that this molecule has the tendency to induce programmed cell death which can lead to breast cancer cell suicide lead- 
ing to its antiproliferative effects. Girinimbine led to the increase of both early and late apoptotic cells. Girinimbine mode of action was further shown to be mediated via decreasing $\mathrm{Bcl}-2$ expression and increasing Bax expression. Finally, it was shown that girinimbine molecule could also inhibit MEK/ERK and STAT3 signalling pathways. These pathways are very crucial and control the cell growth at the basic biochemical levels ( $\mathrm{Li}$ et al., 2016). In the published literature, there are reports of apoptosis induction by molecules which are similar to girinimbine (being a carbazole alkaloid) and as such complement the current findings (Nair et al., 2016).

\section{CONCLUSION}

In conclusion, the results of this study confirmed the promising anti-tumor and pro-apoptotic properties of girinimbine against MDA-MB-453 cells. The current research also confirms that girinimbine could inhibit cancer cell migration and invasion along with targeting key cancer pathways namely MEK/ERK and STAT3 signalling pathways. Therefore, our research could be a breakthrough in treatment of invasive breast cancer however more in vivo and clinical studies are required.

\section{REFERENCES}

Joshi BS, Kamat VN, Gawad DH (1970). On the structures of girinimbine, mahanimbine, isomahanimbine, koenimbidine and murrayacine. Tetrabedron 26: 1475-1482. https://doi.org/10.1016/S00404020(01)92976-X

Chang L, Weiner LS, Hartman SJ, Horvath S, Jeste D, Mischel PS, Kado DM (2019) Breast cancer treatment and its effects on aging. J Geriatr Oncol 10: 346-355. https://doi.org/10.1016/j.jgo.2018.07.010

Chaudhary A (2020) A Review on the Culinary Uses and Therapeutic Properties of Murraya koenigii. J Adv Pharmacognosy 1: 1-8

Daniel PT, Koert U, Schuppan J (2006) Apoptolidin: induction of apoptosis by a natural product. Angew Chem Int Ed Engl 45: 872-893. https://doi.org/10.1002/anie.200502698

Fan S, Li X, Lin J, Chen S, Shan J, Qi G (2014) Honokiol inhibits tumor necrosis factor-alpha-stimulated rat aortic smooth muscle cell proliferation via caspase-and mitochondrial-dependent apoptosis. Inflammation 37: 17-26. https://doi.org/10.1007/s10753-013-9707-y

Goswamia RB, Singha PKS, Goswamib N, Thomasd P, Devic PU, Pathakd AK (2010) Studies on antigenotoxic effect of Murraya koenigii leaves. Int J Pharma Recent Res 2: 65-68

Hu G, Liu H, Wang M, Peng W (2019) IQ Motif Containing GTPaseActivating Protein 3 (IQGAP3) Inhibits kaempferol-induced apoptosis in breast cancer cells by extracellular signal-regulated kinases 1/2 (ERK1/2) signaling activation. Med Sci Monit 25: 7666-7674. https://doi.org/10.12659/MSM.915642

Iman V, Karimian H, Mohan S, Hobani YH, Noordin MI, Mustafa MR, Noor SM (2015) In vitro and in vivo anti-angiogenic activity of girinimbine isolated from Murraya koenigii. Drug Des Devel Ther 9: 1281. https://doi.org/10.2147/DDDT.S71557

Iman V, Mohan S, Abdelwahab SI, Karimian H, Nordin N, Fadaeinasab M, Noordin MI, Noor SM (2017) Anticancer and anti-inflammatory activities of girinimbine isolated from Murraya koenigii. Drug Des Devel Ther 11: 103. https://doi.org/10.2147/DDDT.S115135

Khursheed A, Jain V (2020) Medicinal research progress of natural coumarin and its derivatives. Nat Prod J 10: 1. https://doi.org/10.21 74/2210315510999201102201552

Kok YY, Mooi LY, Ahmad K, Sukari MA, Mat N, Rahmani M, Ali AM (2012) Anti-tumour promoting activity and antioxidant properties of girinimbine isolated from the stem bark of Murraya koenigii S. Molecules 17: 4651-4660. https://doi.org/10.3390/molecules 17044651
Li L, Zhao GD, Shi Z, Qi LL, Zhou LY, Fu ZX (2016) The Ras/ Raf/MEK/ERK signaling pathway and its role in the occurrence and development of HCC. Oncol Lett 12: 3045-3050. https://doi. org/10.3892/ol.2016.5110

Li YZ, Li CJ, Pinto AV, Pardee AB (1995) Release of mitochondria cytochrome $\mathrm{C}$ in both apoptosis and necrosis-induced by -lapachone in human carcinoma cells. Mol Med 5: 232-239

Liu K, Zang Y, Shen C, Li C, Ma J, Yang J, Sun X, Chen X, Wang N, Zhang D (2021) Synthesis and biological evaluation of pyranocarbazole derivatives as Anti-tumor agents. Bioorg Med Chem Lett 33: 127739. https://doi.org/10.1016/j.bmcl.2020.127739

Mohan S, Abdelwahab SI, Cheah SC, Sukari MA, Syam S, Shamsuddin N, Rais Mustafa M (2013) Apoptosis effect of girinimbine isolated from Murraya koenigii on lung cancer cells in vitro. Evid Based Complement Alternat Med 2013: 1-12. https://doi.org/10.1155/2013/689865

Morrow M, Jordan VC, Takei H, Gradishar WJ, Pierce LJ (1999) Current controversies in breast cancer management. Curr Probl Surg 36: 163-216

Nair JJ, van Staden J, Bastida J (2016) Apoptosis-inducing effects of amaryllidaceae alkaloids. Curr Med Chem 23: 161-185. https://doi.or $\mathrm{g} / 10.2174 / 0929867323666151118121124$

Norton L (1999) Adjuvant breast cancer therapy: current status and future strategies - growth kinetics and the improved drug therapy of breast cancer. Semin Oncol 26: 1-4

Ramsewak RS, Nair MG, Strasburg GM, DeWitt DL, Nitiss JL (1999) Biologically active carbazole alkaloids from Murraya koenigii. J Agric Food Chem 47: 444-7. https://doi.org/10.1021/jf9805808

Richard MA, Westcombe AM, Love SB, Little johns P, Ramirez AJ (1999) Influence of delay on survival in patients with breast cancer: a systemic review. Lancet 353: 1119-1126. https://doi.org/10.1016/ s0140-6736(99)02143-1

Ruppert JM, Wright M, Rosenfeld M, Grushcow G, Bilbao G, Curiel DT, Strong TV (1997) Gene therapy strategies for carcinoma of the breast. Breast Cancer Res Treat 44: 93-114. https://doi. org/10.1023/A:1005761723853

Shah AS, Wakade AS, Juvekar AR (2008) Immunomodulatory activity of methanolic extract of Murraya koenigii (L) Spreng leaves. Indian J Exp Biol 46: 505-509

Sharma GN, Dave R, Sanadya J, Sharma P, Sharma KK (2010) Various types and management of breast cancer: an overview. $J A d v$ Pharm Technol Res 1: 109

Siegel RL, Miller KD, Jemal A (2016) Cancer statistics, 2016. CA Cancer I Clin 66: 7-30. https://doi.org/10.3322/caac.21332

Songue JL, Dongo E, Mpondo TN, White RL (2012) Chemical constituents from stem bark and roots of Clausena anisata. Molecules 17: 13673-1386. https://doi.org/10.3390/molecules171113673

Syam S, Abdul AB, Sukari M, Mohan S, Abdelwahab SI, Wah TS (2011) The growth suppressing effects of girinimbine on HepG2 involve induction of apoptosis and cell cycle arrest. Molecules 16: 7155-7170. https://doi.org/10.3390/molecules16087155

Vranic S, Gatalica Z, Wang ZY (2011) Update on the molecular profile of the MDA-MB-453 cell line as a model for apocrine breast carcinoma studies. Oncol Lett 2: 1131-1137. https://doi.org/10.3892/ ol.2011.375

Wang SL, Cai B, Cui CB, Yan SY, Wu CF (2007) Induction of apoptosis by girinimbine in K562 cell. Zhong Cao Yao 38: 1677-1681

Wang X, Beitler JJ, Wang H, Lee MJ, Huang W, Koenig L, Nannapaneni S, Amin AR, Bonner M, Shin HJ, Chen ZG (2014) Honokiol enhances paclitaxel efficacy in multi-drug resistant human cancer model through the induction of apoptosis. PLOS ONE 9: e86369. https://doi.org/10.1371/journal.pone.0086369

Wu Z, Wang C, Huang M, Tao Z, Yan W Du Y (2019) Naturally occurring sesquiterpene lactone-santonin, exerts anticancer effects in multi-drug resistant breast cancer cells by inducing mitochondrial mediated apoptosis, caspase activation, cell cycle arrest, and by targeting Ras/Raf/MEK/ERK signaling pathway. Med Sci Monit 25: 3676-3682. https://doi.org/10.12659/MSM.915246

Xin Q, Muer A (2018) Girinimbine inhibits the proliferation of human ovarian cancer cells in vitro via the phosphatidylinositol-3-kinase (PI3K)/akt and the mammalian target of rapamycin (mTOR) and Wnt/ $\beta$-catenin signaling pathways. Med Sci Mon Int Med J Exp Clin Res 24: 5480-5487. https://doi.org/10.12659/MSM.931225 